\title{
Thermal performance of wooden elements exposed to microwave radiation during treatment of building defects
}

\author{
Jindřich Sobotka ${ }^{1, *}$, and Radim Smolka ${ }^{1}$ \\ ${ }^{1}$ Brno University of Technology, Faculty of Civil Engineering, \\ Institute of Building Structures, Veveř́ 95, 60200 Brno, Czech Republic
}

\begin{abstract}
The paper describes application and theory of microwave radiation and experimental optimization of microwave radiation in relation to its growth of temperature inside and outside of wooden elements. The effect of microwave radiation on building structures is first manifested by vibration of water molecules contained in the material, which leads to a change of the state of matter from liquid to steam, which then evaporates from the wet material. During the transformation of energy from liquid state of matter to steam, heat is generated, therefore, wooden elements heat up. Therefore, the irradiated element, a wooden one in this case, gets dried up. More precisely, the paper assesses the effect of the heating times and distance of heated material from the microwave generator (antenna) and reached temperatures on the surface and inside of the irradiated spruce elements. Individual experiments were performed and results were evaluated for all wooden elements. Wooden samples were divided into two groups. Individual groups were exposed to microwave radiation for different times. In total there were two groups of spruce samples, where individual elements were exposed to identical ambient (outdoor) conditions for a long time.
\end{abstract}

\section{Introduction}

Microwave is known as a part of electromagnetic radiation with a frequency from $300 \mathrm{MHz}$ to $300 \mathrm{GHz}$, corresponding to wavelengths from $1 \mathrm{~m}$ to $1 \mathrm{~mm}$. For industrial purposes it is globally determined by the frequency of $2.45 \mathrm{GHz}$, corresponding to a wavelength of 12.2 $\mathrm{cm}$. Such wavelength is also used in our applications [1].

Microwave Technology (EMW technology) is used in construction mainly for drying of damp structures, or as a way of disposal of biotic pests. In most cases, when heating the material, only the surface temperature of the front side is controlled. Temperatures reached at a depth are only estimated. And it is actually a heating depth and a distribution of temperature field that has a major impact on the speed and quality of the performed remediation. Without sufficient knowledge about how the material is heated, there is a risk of damage of the drying material [2].

\footnotetext{
*Corresponding author: sobotka.j@ffce.vutbr.cz
} 
Microwaves belong to the broad spectrum of electromagnetic waves, which also include a visible light region which is governed by Maxwell's equations.

It is applied, that the vectors characterizing the magnetic and electric fields are in every point and in every moment perpendicular to each other and both are perpendicular to the direction of wave motion (Fig. 1).

Their amplitudes have a constant ratio and in a vacuum, the electromagnetic waves move with a speed of light and so the following relation is applied:

where: $\quad \lambda \quad$ length of wave $(\mathrm{m})$

$$
\lambda=\frac{c_{\lambda}}{f}
$$

$\mathrm{c}_{\lambda} \quad$ velocity of wave propagation $\left(\mathrm{m} \cdot \mathrm{s}^{-1}\right)$

f frequency of microwave radiation $(\mathrm{Hz})-(2450 \mathrm{MHz})$. [1]

In assessing the possibility of using microwave technology in civil engineering practice it is necessary to realize the following aspects:

- the law of conservation of energy always applies;

- the microwave radiation penetrates some materials (glass, porcelain, ceramics, concrete, wood);

- certain material is by EMW radiation reflected (metals);

- by some materials the radiation is "absorbed" (water).

The changeover mechanism of the microwave energy to heat is given by:

$$
\mathrm{P}=2 \cdot \pi \cdot \mathrm{f} \cdot \varepsilon^{\prime} \cdot \varepsilon^{\prime \prime} \cdot \mathrm{E}^{2}
$$

where: $\quad \mathrm{P}$ energy absorbed per unit volume $\left(\mathrm{W} \cdot \mathrm{m}^{-1}\right)$,
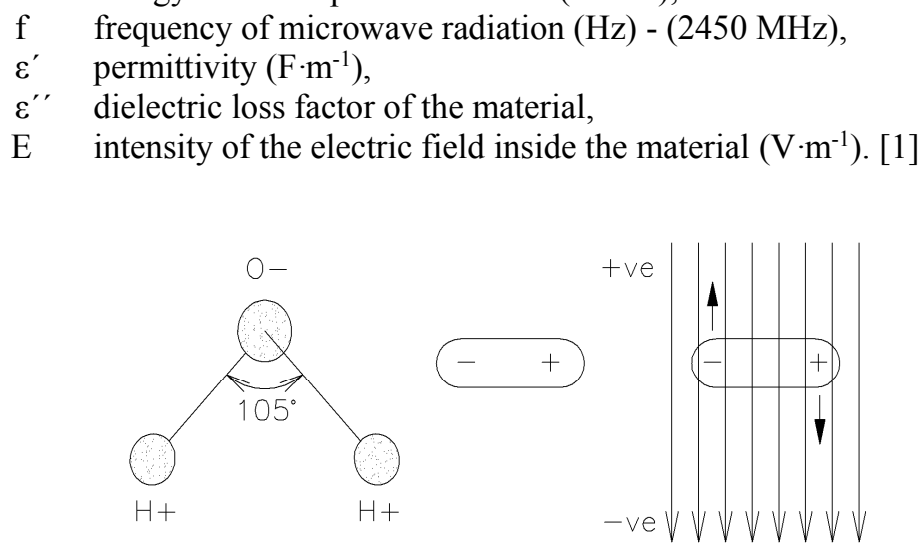

Fig.1. Water molecule and its orientation in an electric field [5]

In the process, it is necessary to realize that water molecules tend to adjust their polarities changing the polarity of the electromagnetic microwave flux. This leads to the electromagnetic transformation of energy in kinetic energy. Fast movement of molecules and their mutual rubbing is subsequent kinetic energy converted into thermal energy.

Most electromagnetic energy is absorbed and converted to heat energy by the water molecules, which will first come into contact with. The greater the distance of water molecules from the front of the irradiated side is, the less is the flow of electromagnetic energy acting upon them and also its heating.

Following factors have a major impact on the depth of the microwaves penetration:

- water content and its distribution, [3]

- performance of the equipment used. [4], [5]. 


\section{Experiment description}

Two groups of 9 pieces of planed spruce samples with the cross-section of $120 \times 60 \mathrm{~mm}$ were used for the experiment. Samples of identical or very similar cross-sections are used for prefabricated wooden houses. The used elements were placed under a shelter and exposed to external weather conditions for the time period of three months (November January).

After the end of each individual heating the following were measured:

1. surface temperature on the face side,

2. temperature inside of the element, $40 \mathrm{~mm}$ from the face side,

3. temperature inside of the element, $80 \mathrm{~mm}$ from the face side,

4. temperature of the rear (reverse) side.

The samples were divided into 6 groups of 3 pcs. Each group of elements was heated under different conditions. The arithmetic average was calculated from the measured values.

During the first part of the experiments the heated element was placed in the distance of $5 \mathrm{~mm}$ from the device antenna, and only the heating time kept changing.

Used measuring devices:

- MB elekronic - power input $1150 \mathrm{~W}$, radiating power $750 \mathrm{~W}$,

- infrared camera FLIR 6,

- thermometer Greisinger GMH 1170 + penetration probe $\mathrm{l}=120 \mathrm{~mm}$.

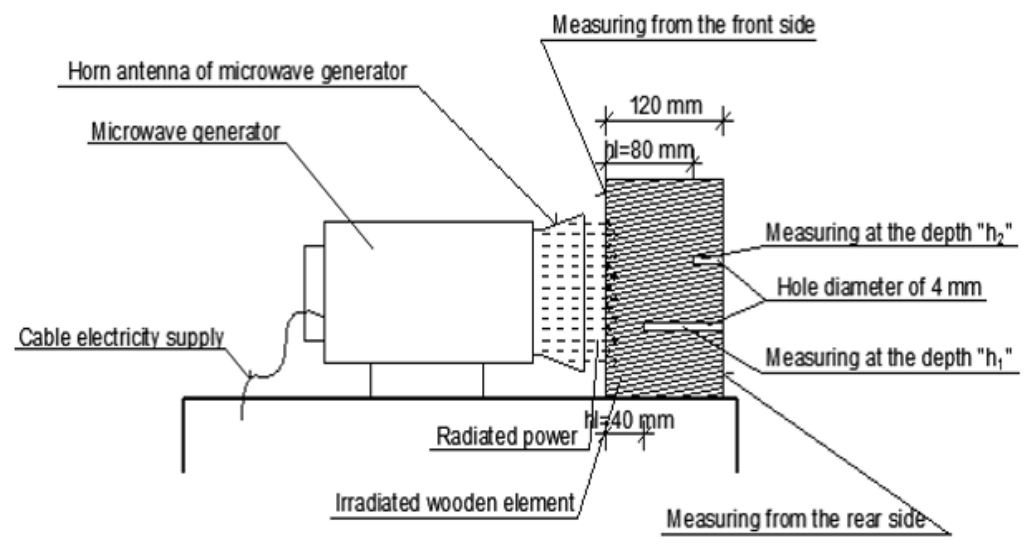

Fig. 2. View of diagram of wood element during irradiation

\subsection{Set 1 of experiments}

Moisture of individual elements $12.2-13.1 \%$, temperature $20.6{ }^{\circ} \mathrm{C}$.

Internal environment in laboratory: air temperature $21.9^{\circ} \mathrm{C}$, relative humidity $52 \%$.

Distance of the irradiated element from antenna was set to $5 \mathrm{~mm}$. Heating times were 5,10 , 15 minutes. 
Table 1. Table of three groups of elements with different heating times

\begin{tabular}{|c|c|c|c|c|}
\hline Element No. & face side $\left[{ }^{\circ} \mathrm{C}\right]$ & $\begin{array}{c}\mathrm{h} 1=40 \mathrm{~mm} \text { from face } \\
\text { side }\left[{ }^{\circ} \mathrm{C}\right]\end{array}$ & $\begin{array}{c}\mathrm{h} 2=80 \mathrm{~mm} \text { from } \\
\text { face side }\left[{ }^{\circ} \mathrm{C}\right]\end{array}$ & rear side $\left[{ }^{\circ} \mathrm{C}\right]$ \\
\hline
\end{tabular}

1. heating 5 minutes

\begin{tabular}{|c|c|c|c|c|}
\hline No.1 & 84.3 & 72.6 & 59.2 & 37.7 \\
\hline No.2 & 73.0 & 66.8 & 41.8 & 37.4 \\
\hline No.3 & 79.2 & 81.4 & 45.4 & 37.8 \\
\hline Average No.1 - 3 & $\mathbf{7 8 . 8}$ & $\mathbf{7 3 . 6}$ & $\mathbf{4 8 . 8}$ & $\mathbf{3 7 . 6}$ \\
\hline
\end{tabular}

2. heating 10 minutes

\begin{tabular}{|c|c|c|c|c|}
\hline No.4 & 91.1 & 104.1 & 85.2 & 80.7 \\
\hline No.5 & 82.4 & 98.4 & 82.4 & 79.1 \\
\hline No.6 & 89.9 & 103.4 & 86.8 & 80.3 \\
\hline Average No.4 - 6 & $\mathbf{8 7 . 8}$ & $\mathbf{1 0 2}$ & $\mathbf{8 4 . 8}$ & $\mathbf{8 0 . 0}$ \\
\hline
\end{tabular}

3. heating 15 minutes

\begin{tabular}{|c|c|c|c|c|}
\hline No.7 & 92.0 & 124.0 & 97.9 & 98.6 \\
\hline No.8 & 103.1 & 119.4 & 99.4 & 99.1 \\
\hline No.9 & 94.1 & 128.2 & 98.8 & 99.1 \\
\hline Average No.7 - 9 & $\mathbf{9 6 . 4}$ & $\mathbf{1 2 3 . 9}$ & $\mathbf{9 8 . 7}$ & $\mathbf{9 8 . 9}$ \\
\hline
\end{tabular}

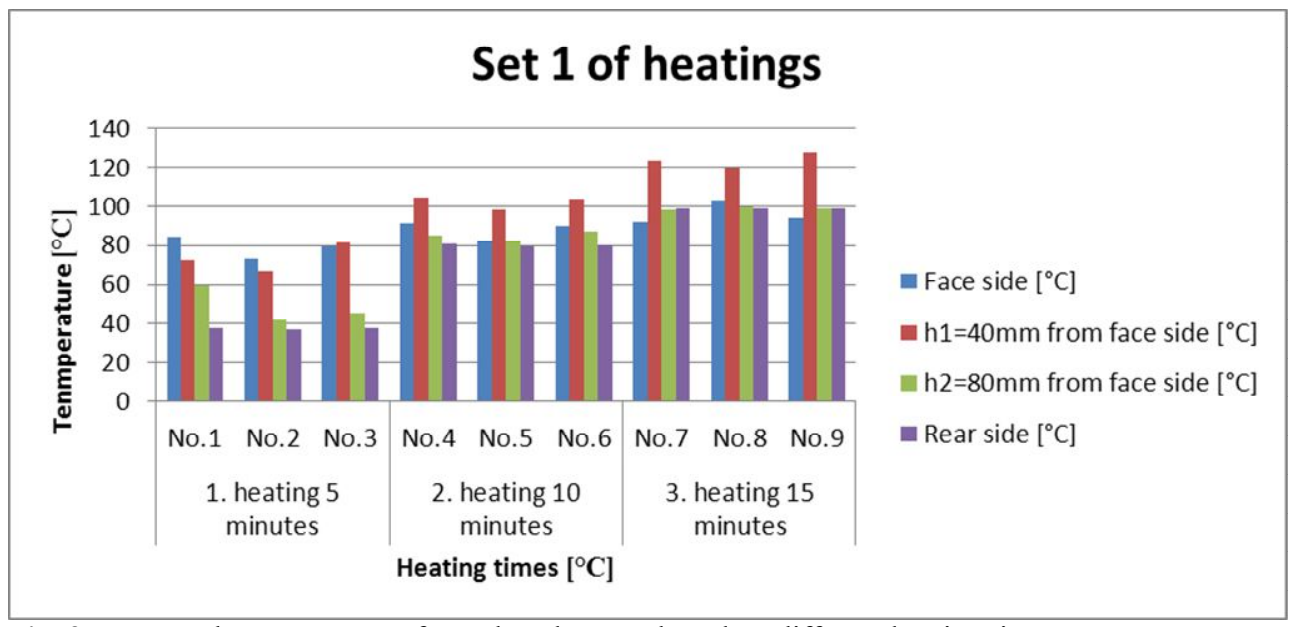

Fig. 3. Measured temperatures of wooden elements based on different heating times

\subsection{Set 2 of experiments}

In the second part the heating was identical, but the distance of wooden elements from the antenna changed.

Distance of the irradiated element and the antenna 50,100, $150 \mathrm{~mm}$.

Heating time 10 minutes. 
Table 2. Measured distances of element groups - generator antenna and wooden element

\begin{tabular}{|c|c|c|c|c|}
\hline Element No. & face side $\left[{ }^{\circ} \mathrm{C}\right]$ & $\begin{array}{c}\mathrm{h} 1=40 \mathrm{~mm} \text { from face } \\
\text { side }\left[{ }^{\circ} \mathrm{C}\right]\end{array}$ & $\begin{array}{c}\mathrm{h} 2=\mathbf{8 0} \mathbf{~ m m} \text { from face } \\
\text { side }\left[{ }^{\circ} \mathrm{C}\right]\end{array}$ & rear side $\left[{ }^{\circ} \mathrm{C}\right]$ \\
\hline
\end{tabular}

2. distance from antenna $5 \mathrm{~mm}$

\begin{tabular}{|c|c|c|c|c|}
\hline No.4 & 91.1 & 104.1 & 85.2 & 80.7 \\
\hline No.5 & 82.4 & 98.4 & 82.4 & 79.1 \\
\hline No.6 & 89.9 & 103.4 & 86.8 & 80.3 \\
\hline Average No.4 - 6 & $\mathbf{8 7 . 8}$ & $\mathbf{1 0 2}$ & $\mathbf{8 4 . 8}$ & $\mathbf{8 0 . 0}$ \\
\hline
\end{tabular}

5. distance from antenna $50 \mathrm{~mm}$

\begin{tabular}{|c|c|c|c|c|}
\hline No.10 & 90.1 & 98.1 & 93.8 & 83.8 \\
\hline No.11 & 80.1 & 97.5 & 91.9 & 63.9 \\
\hline No.12 & 83.9 & 97.8 & 89.2 & 78.9 \\
\hline Average No. 10 - 12 & $\mathbf{8 4 . 7}$ & $\mathbf{9 7 . 8}$ & $\mathbf{9 1 . 6}$ & $\mathbf{7 5 . 5}$ \\
\hline
\end{tabular}

6. distance from antenna $100 \mathrm{~mm}$

\begin{tabular}{|c|c|c|c|c|}
\hline No.13 & 73.3 & 95.8 & 58.5 & 39.8 \\
\hline No.14 & 76.6 & 93.5 & 52.5 & 34.2 \\
\hline No.15 & 77.0 & 86.8 & 45.5 & 39.9 \\
\hline Average No.13 - 15 & $\mathbf{7 5 . 6}$ & $\mathbf{9 2}$ & $\mathbf{5 1 . 2}$ & $\mathbf{3 7 . 9}$ \\
\hline
\end{tabular}

7. distance from antenna $150 \mathrm{~mm}$

\begin{tabular}{|c|c|c|c|c|}
\hline No.16 & 58.4 & 52.5 & 23.4 & 35.1 \\
\hline No.17 & 63.3 & 49.4 & 26.6 & 33.1 \\
\hline No.18 & 60.2 & 51.9 & 28.5 & 31.7 \\
\hline Average No.16 - 18 & $\mathbf{6 0 . 6}$ & $\mathbf{5 1 . 3}$ & $\mathbf{2 6 . 2}$ & $\mathbf{3 3 . 3}$ \\
\hline
\end{tabular}

\section{Data analysis, evaluation}

Microwave energy transmitted by a magnetron is directed by a directional antenna. Its shape is a compromise of different requirements so that it was as versatile as possible. This is a cause of nonhomogeneous coverage of the irradiated area. With longer distance of the antenna from the irradiated area dispersion of electromagnetic waves occurs, their density decreases, and consequently the amount of energy falling on a unit of the irradiated area decreases as well. [4] [6]

\section{Conclusion}

The measured data imply:

In the first phase of Set 1 and 2 of radiation experiments, the electromagnetic energy is transformed into thermal energy and consequently into heating of face side layers. The reached temperatures decrease dramatically with growing depth.

The increase of temperature of face layers results in:

- higher evaporation of water from the surface, 
- increase in water temperature inside of the material changes its volume. The generated overpressure works in all directions, even towards the surface.

- drying of face layers,

- the fact that vibrating water molecules contained in the material received enough energy. results in lower absorption of the microwave energy which can thus travel deeper.

Regarding intensive or long-standing heating, when temperatures over $100^{\circ} \mathrm{C}$ are reached, there is a threat of undesirable pressure of water vapours and consequent damage of drying material.

An important factor of microwave energy usability is a distance of the generator antenna and the irradiated wooden element.

As obvious from Set 2 of the experiments, the usability of microwave energy decreases with the growing distance between the antenna and the wooden element. The clear indicator are the measured decreasing temperature values of the wooden elements.

This paper has been worked out under the project No. LO1408 "AdMaS UP - Advanced Materials, Structures and Technologies", supported by Ministry of Education, Youth and Sports under the "National Sustainability Programme I".

\section{References}

1. M. Novotny, K. Suhajda, J. Sobotka, J. Gintar, E. Suhajdova, M. Matl, Z. Jirousek, Wood Res-Slovakia, 59/3, 389-400 (2014)

2. J. Sobotka, R. Smolka, MATEC Web of Conferences, 93, 01008 (2016)

3. M. Prochazka, J. Sobotka, Trans Tech Publications (Trans Tech Publications, 2016)

4. J. Sobotka, R. Kolar, Applied Mechanics and Materials, (Trans Tech Publications, 2016)

5. D. Beckovsky, L. Vackova, T. Beckovska, J. Sobotka, J. Pencik, M. Lavicky, Wood Res-Slovakia, 61/4, 627-635 (2016)

6. J. Sobotka, R. Smolka, MATEC Web of Conferences, 146, 03008 (2018) 